\title{
REFLECTION AS A MEANS FOR LEARNING SKILL IMPROVEMENT IN STUDENTS
}

\section{Iveta Kāposta}

Rīgas Pedagoǵijas un izglītības vadības akadēmija

\begin{abstract}
Self-regulation is one of the criteria in good or competent learning. Self-regulated learning means that the learning person understands the process of one's learning i.e. understands what one needs; understands what happens to one during such learning; one is responsible for own learning; one has acquired and independently applies learning skills. Many scholars regard reflection as being means for improvement of competent learning. Reflection in pedagogy is to be understood as a process of awareness the performance and / or action which took place in educational process or any part. Reflection is based on analysis of one's actions and/or activities. Reflection may differ both in terms of the goal as well as in terms of the subject across various stages of learning process and activities. Russian educator and psychologist A. Stepanova classifies reflection in accordance with the subject of reflection (Степанова, 2009): mood and emotional status reflection; reflection of learning content; learning activity reflection. Mood and emotional status reflection and learning content reflection are often applied in Latvian schools; while reflection on learning activities has enjoyed little recognition. Educators in Latvian schools often offer students use questions and visualisation as methods of reflection (latter is used in work with younger students), but negotiations are offer relatively rare. Educators recognise reflection better according to the actions but they lack knowledge on reflection during action thus not offering it to students. Nevertheless, some secondary education students use reflection during action in an unaware manner. Reflection on average is given 5 - 10 minutes during a lesson.
\end{abstract}

Keywords: analysis, feedback, learning, learning skills, reflection

\section{Introduction}

One of the principles attributable to the results of learning process is introduction to self-education or transition to self-education. This principle has become especially important currently as the social goal of education is a formation of a learning capable society. Every individual in such learning capable society has an inherent understanding on the importance of learning. Such understanding thus describes competent learning. In order to achieve the goal of learning capable society, the student must acquire learning skills - the foundation of competent learning. Many scholars (Meyer, 2004; Schön, 1983; Dirks, 2000; Neuweg, 1999; Степанова, 2009; Moon, 2004) regard reflection as an important means for improvement of learning skills. The goal of the present study is to describe the types and opportunities of reflection for improvement of student learning skills as well as to analyse the experience of teachers in Latvian schools on the use of reflection during lessons. 


\section{Methods and means}

In order to determine how reflection is used for promotion of student learning skills during learning process, literature and experience of Latvian teachers was analysed: lessons were observed and analyse (43 respondents); lesson plans were analysed ( 86 respondents); students of various age groups were surveyed (2008 respondents) as well as teachers working with various class groups (69 respondents).

\section{Results and discussion}

Learning as one of the principal elements if learning process is a complex selfdeveloping system). Studies by D. Kolb (Kolb, 1984) have shown that learning is described as a continuous process based on the experience of each individual. Learning is associated with the interaction between the individual and the environment, during which experience and action transforms into knowledge. In order to achieve such result one must know how to learn. Didactics have been used the term of competent learning as opposed to incompetent learning for quite a while (when a person does not know how to learn and takes part in the process intuitively or under the strict management and control of the teacher).

Ann Gertsma and Barry J.Hake (2004) have defined criteria of competent learning that also characterises the process of learning in the meantime. Good learning includes:

- active construction of knowledge;

- accumulation of knowledge and formation of interrelations;

- self-regulation,

- cooperation.

Each of these criteria expresses itself in a different way during the learning process. In the course of this paper, we will review learning as a self-regulated process due to the fact that this criterion also includes learning skills which is the subject of the present study.

Self-regulated learning means that a person learning understands one's learning:

1. understands why he needs it (a conscious learning goal, conscious learning motivation, diverse learning approaches acquired and a skill to select approaches suitable for the goal etc.);

2. understands what happens to one during learning;

3. responsible for one's learning;

4. has mastered and continuously improves learning skills.

However, the said understanding and skills are not acquired through themselves. There are even grown ups the learning competency of which is very low thus they are unable to learn by themselves.

Part of the society believes by consciously performing various learning tasks, learning skills develop inherently, while research (Meyer, 2004; Kolb, 1984) 
shows that this could not be further from truth. Learning skills must be constantly created and improved. It is an integral part in the process of learning to learn. In their research on effective means for promotion of self-regulated learning, Scholars (Meyer, 2004; Schön, 1983; Dirks, 2000; Neuweg, 1999; Степанова, 2009; Moon, 2004) give recognition to reflection.

Reflection (lat. reflexio - turning back) - is a process of man's theoretical action in which he understands one's actions and law.

There are three types of reflection:

1. elementary reflection (analyses actions and knowledge, resolves considerations on the boundaries and the meaning thereof);

2. scientific reflection (critical analysis of theoretical knowledge with the use of such methods and approaches that are characteristic to the respective science;

3. philosophical reflection (awareness of the fundamentals of thinking, existence, humanity and culture) [http://www.letonika.lv/].

There are two primary types to be considered in the learning process. During the primary and elementary part of education, reflection takes place on the basis of elementary reflection and it is organised on the part of the teachers accordingly, but during the later stages of education, scientific reflection may also be used. Depending on the specific goal, teachers may use both the first as well as the second type for own professional development.

Reflection in pedagogy is to be understood as a process of awareness the performance and/or action which took place in educational process or any part. Reflection as it is seen from the description of the term is based on the analysis of own actions and/or activities in order to understand and associate the obtained result, set goals and the suitability thereof with one's character and opportunities etc. It may be said that reflection is a form of feedback given to oneself.

In the pedagogical literature reflection is often reviewed in conjunction with feedback and communication. Upon describing a good lesson, H.Meyer (2004) indicates that an exhaustive communication is among the criteria for a successful lesson. One of the aspects of communication during lesson is feedback which may be promoted via

- learning diaries;

- learning portfolio;

- feeling conferences;

- workshops;

- conversations about the assistance provided.

Upon successful combination during the learning process of the said type, as well as by selecting methods appropriate to each, it is possible to facilitate the learning motivation of students, interest in the specific topic, subject and studies as such as well as reflection on the learning process which as indicated by H.Meyer (2004) assist both directly and indirectly to form the alliance of learning. 
In order for reflection to provide maximum result, it is crucial for the reflectee to be able and to have the skill to determine what D. Schoen (Schön, 1983) refers to as reflective distance i.e. divide one's practice from the actions of other persons involved in the process. This skill may be acquired via through a continuous training and mastery of various reflection approaches.

Depending on the time when reflection takes place, the two following types may be distinguished: reflection according to the action and reflection during action. Reflection according to the action or reflection on activities (Reflexsion - über Handlung) is the simplest and consciously the most often used type. During this type of reflection, action is analysed in a retrospective and methodologically controlled manner, furthermore, actions are often structured in a new way thus the action experience transform into a new knowledge thereof (Dirks, 2000).

When the specific level of knowledge has been reached on one's actions during various situations, one may also use the other type of reflection as described D. Schoen (Schön, 1983): reflection during action (Reflexsion - in - der Handlung). This type of reflection is characterised by having a point of start as a specific situation in which one must act with the usual models of action not being applicable. In order to act one must first of all understand the unknown situation, after that selecting an alternative or a means of action not used as of so far. Such type of reflection is also used quite often, but it does always take place consciously.

Depending on the goal and skill of the reflectee, reflection may be implemented both individually, as well as in group or in a collective (large group).

During learning process, reflection is most often organised by the teacher who depending on the learning goal, age of the students and reflection experience and skills, offers one of the types and methods of reflection. However, students upon being involved in the reflection organised by the teacher, are oriented towards their own learning goal.

Reflection may differ both in terms of the goal as well as in terms of the subject across various stages of learning process and activities.

Russian education and psychologist A.Stepanova classified reflection in accordance with the object of reflection (Степанова, 2009):

- Mood and emotional state reflection.

This is often organised by the teacher at the beginning of the lesson in order to establish an emotional contact with the group and/or to create a specific emotional background and at the end of the lesson - in order to allow realising and a sense of fulfilment for the work as well as to emphasise the individual learning achievements of the students. Thus conditions favourable for the stabilisation of learning motivation are created.

- Reflection of learning content.

It is often organised for the teacher to be able to get a feedback on how students have understood the content acquired during a lesson or set of lessons. In this case, also the individual learning achievements are established and accepted. It 
directly influences specific learning motives and facilitates development of conscious learning motivation.

- Reflection of learning actions.

It is organised so the students would realise the relation between the specific learning actions (approaches, methods, forms) with the result obtained. It is necessary for the student to understand the meaning of specific actions allowing to be able and capable to choose reasonable learning approaches, actions and methods for one to summarise and personalise one's learning experience, be able to create own learning strategy and realise and/or improve one's learning schools. Thus the learning competency of a student is improved.

In order to understand how these types of reflection are used during learning process, teachers working with various groups of classes (Form 1 to 4, Form 5 9 , Form 10 - 12), the students of these classes were surveyed as well the lessons were observed and lesson plans were analysed. The results were summarised in Figures 1, 2 and 3.

The number of surveyed students was sufficient to determine proportional relations while the number of teachers was not sufficient for the aforementioned goal, thus the opinion of teachers are expressed in definite numbers.

As presented in Figures 1, 2 and 3, our schools organise mood and emotional state reflection as well as reflection of learning content in a similar amount, while learning action reflection enjoys much less attention.

The proportion of various types of reflection depends on the age group of students: in younger age (Form 1 - 4) more attention is given to mood and emotional state refection, because during this age students perform assessments in an emotional manner, while learning content reflection is given more attention in the middle (Form 5 - 9) and older (Form 10 - 12) age group) when students have sufficiently developed ability to assess in a rational manner.

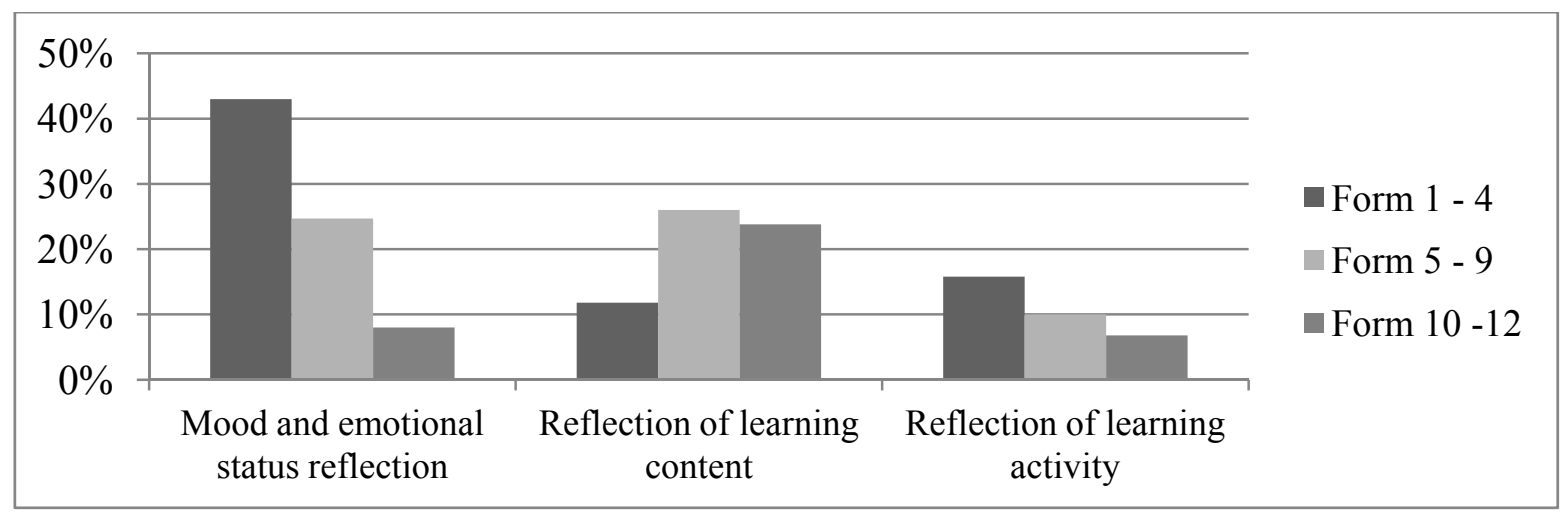

Figure1. Use of reflection types during lessons (observations) 


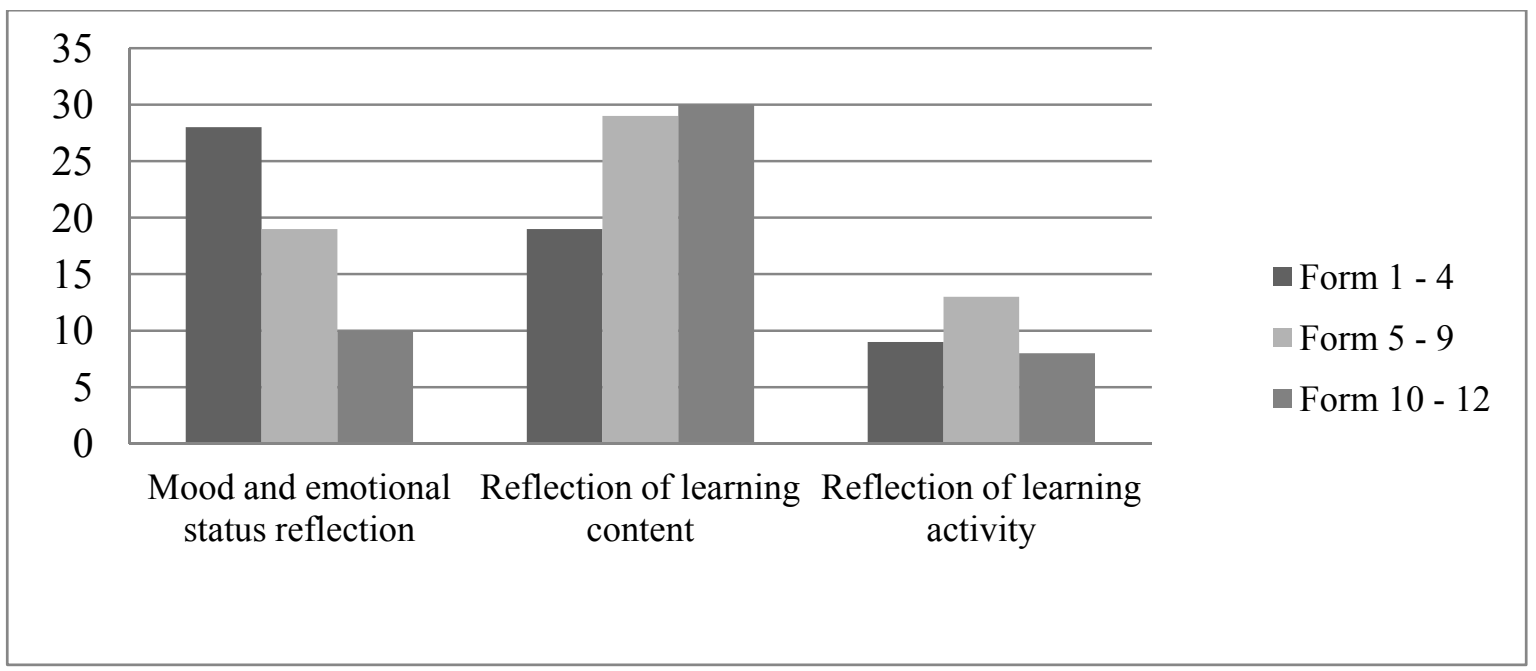

Figure 2. Use of reflection types (teachers' opinion)

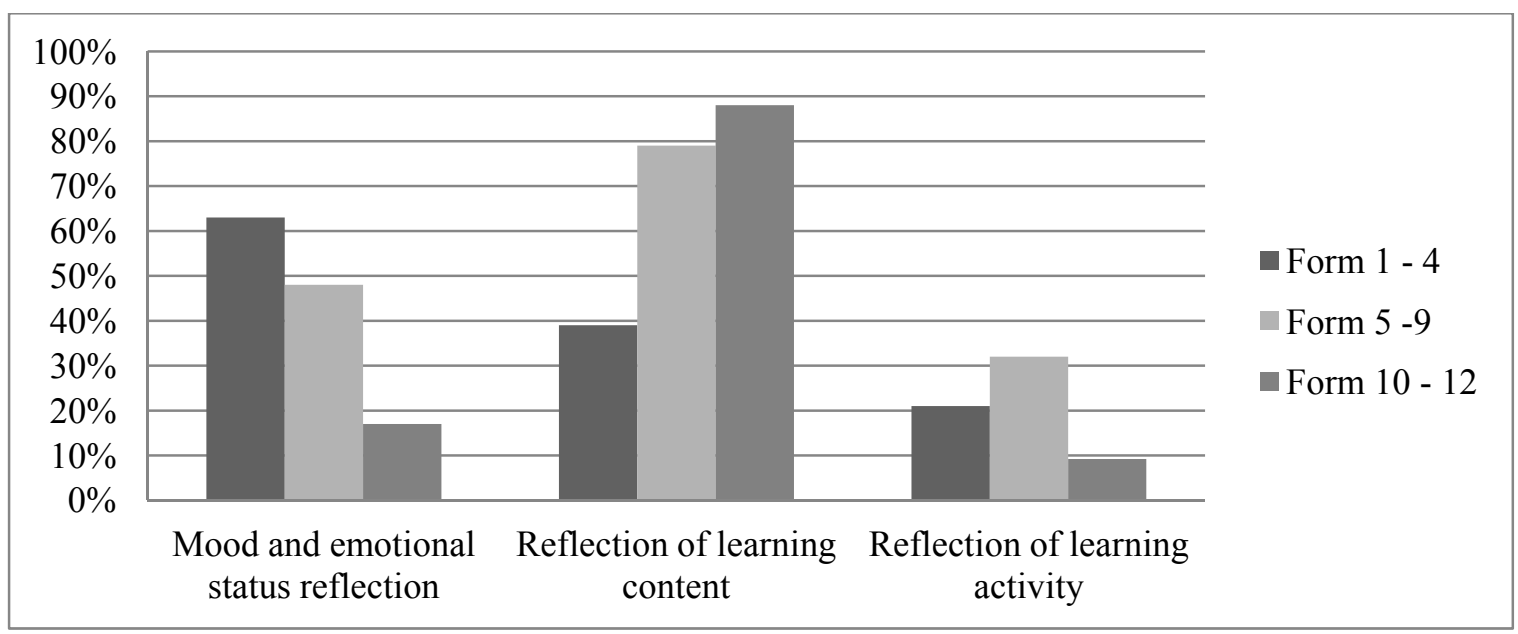

Figure 3. Use of reflection types (students' opinion)

The situation is worse in relation to the reflection of learning activities. (See Figure 1, 2 and 3) This type of reflection is given a lot less attention than the other two types across all age groups.

Teacher survey shows that in teacher's opinion most students have poor learning skills. Teachers indicate that many students do not know how to learn and thus they have difficulties to acquire the learning content, which in turn contributes to the second issue: students have a poorly developed learning motivation. However, teachers are unable to offer a solution, many of them indicating that it is the competency of scholars and education politicans, while the task of the teacher is to organise lessons in order to allow the pupil to acquire the learning content. Some part of teachers indicate that from time to time (others more frequent (even every lesson) than others) students are encouraged to analyse the benefits and/or achievements of the lesson. They indicate that such analysis is attributable to promotion of learning motivation because thus students are able to see the link between own achievements, benefits and the learning content 
more clearly. Hence, teachers use reflection of learning content in a conscious and determined manner.

Most teachers are sceptical towards the necessity of learning activity reflection in the improvement of student learning skills indicating that learning may be only mastered via the process of learning, but talking does not improve learning skills; it is important that students would have an opportunity to try diverse learning methods which is attempted to be provided by the teachers. This statement is quite contradictory to the verities of education and psychology theory.

In education, reflection is expressed as:

- an ability and skill to understand one's actions, first of all, the result, approaches and means that have allowed achieving the result;

- as an ability analyse the means of cognition that are being used. Process and result of understanding the developments of learning process. (Степанова, 2009).

A student should instead of leaving the lesson with a fixed learning result create a clear link between causes and consequences via comparison of methods and approaches applied by one with those used by other students (goal-actionresult). While reflection of learning content allows merely settling the result and compare the initial goal with one's needs.

Learning means (learning approaches, methods, forms) that were accepted, understood and recognised as effective by the student during reflection allow such student to organise and implement one's learning in an efficient manner (hereinafter the student is able to independently select specific goals respective to the learning situation and for the achievement of the learning ask) which will in turn improve learning results as well as they allow student to plan and implement self-development in a determined manner (Степанова, 2009; Meyer, 2004).

Methods that may be used for reflection depending on the type, complexity and goal, type of implementation as well as the age and individual qualities of the students may be as follows:

- questions,

- discussions;

- visualisation,

- audible visualisation,

- structuring (for example, in a table),

- comparison (for example, comparison of goal and result) (Степанова, 2009; Meyer, 2004).

The survey conducted among teachers and students shows that in Latvian schools teachers more often use questions and visualisation for student reflection (latter is used in work with younger age groups), while discussions are relatively rare. Visualisation is often used for the reflection of mood and emotional status. 
Questions most often offered for reflection:

- What did I (you) do?

- What was the goal of what I did?

- What result did I achieve?

- What did I enjoy doing?

- What was I good at?

As it is evident all these questions are mainly oriented towards the initial realisation of the activity and its relation with the result achieved. However, in order to create a clear and persuasive chain of causes and consequences, these questions are insufficient as they are attributable to the first stage of analysis the establishment of facts (See Figure 4). In order for the reflection to effective, it is necessary to create a set of questions that would include not only mutually related questions but also questions that comprise all three stages. Only then may a clear chain of causations may be established.

Teachers indicate that during every given lesson they offer not more than 2 questions for the answers not to take too much of the time. Reflection questions are given 3 - 5 minutes in a lesson. Lesson observations and lesson plan analysis show a slightly better situation: reflection is given 5 - 10 minutes on average. A difference between the opinion of the teachers and observations may be explained with the fact that teachers regard the actions conducted at the end of the lesson for the summary of results as reflection but observations show that some elements of reflection are present starting from the beginning of the lesson.

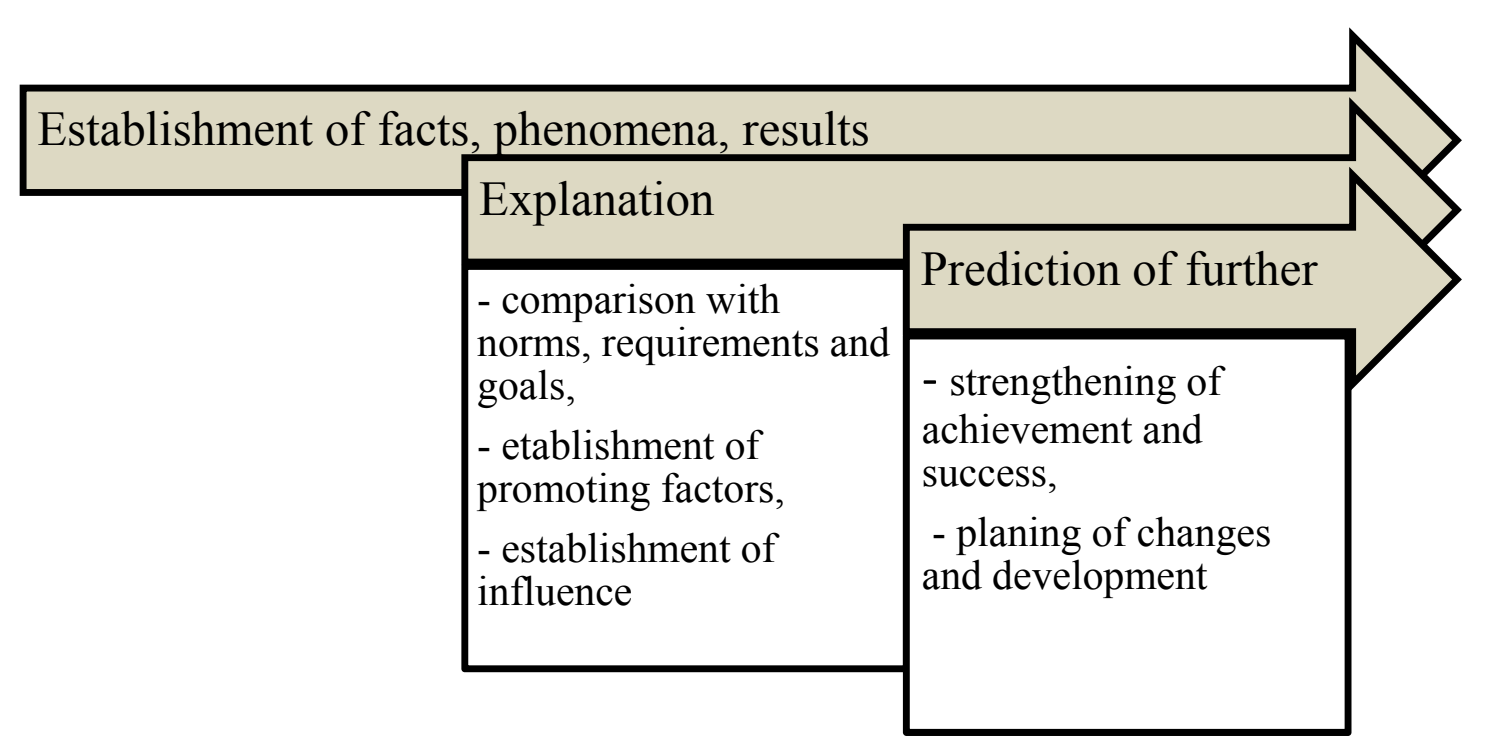

Figure 4. Stages of analysis 
Upon attempting to establish as to how often teachers offer reflection after action and reflection during action, it was revealed that teachers recognise reflection only after action but they lack knowledge on reflection during action.

The survey of secondary school students revealed that some students unwittingly use reflection during action. It takes place during non-standard learning situations, for example, in events when a learning task is given but no instructions for the performance thereof are given by the teacher or when during work according to teacher's recommendations, the student does not achieve the expected result. However, such proportion of students is fairly little - only $12 \%$ of all respondents.

Discussions with educators revealed that not all teachers have sufficient mastery of types, forms and methods of reflection. It is one of the reasons they avoid using them during their educational practice. Some teachers taking part in the survey indicated that questions included in the survey allowed them to ponder on the importance and opportunities of use of reflection during the learning process.

Upon studying the opportunities and importance of reflection during educational process, it is also necessary to pay attention to the reflection skills and experience of teachers as well as to the interrelation between teachers reflection skills and experience with the formation of reflection skills and experience in the student.

\section{Conclusions}

- Student learning skills development most affected reflection of learning actions.

- Latvian schools often use mood and emotional status reflection as well as reflection of learning content. Reflection of learning action is used seldom by the teachers.

- Reflection comprises questions that do not ensure a full cycle of analysis.

- Reflection is used insufficiently during the learning process. In order to ensure that to achieve a reflection of and broader targeted application: Further education programmes for educators must pay attention to the improvement of reflection skills and experience; it is necessary to develop methodical recommendations and/or handbook for teachers for the use of reflection during learning process.

- Further education programmes for educators must pay attention to the improvement of reflection skills and experience.

- It is necessary to develop methodical recommendations and/or handbook for teachers for the use of reflection during learning process. 


\section{References}

1. Dirks, U. (2000). Wie werden EnglischlehrerInnen professionell? Eine Berufsbiographische Untersuchung in den neuen Bundesländern. [How are English teachers professional? A professional biographical investigation in the new federal states.] Münster u.a. Waxmann. (In German).

2. Geertsma, A., Hake, B.J. (2004). Experimenting with Individual Learning Accounts: Making Up the Balance. CINOP

3. Kolb, D. (1984). Experiential learning: experience as the source of learning and development. Prentice-Hall, USA.

4. Meyer, H. (2008). Was ist ein guter Unterricht? [What is a good lesson?] Berlin: Cornelsen Verlag Scriptor GmbH \& Co. (In German).

5. Moon, J.A. (2004). Reflection in Learning and Professional Development: Theory and Practice. Routledge Falmer, USA.

6. Neuweg, G.H. (1999). Könnerschaft und implizites Wissen. Zur lehr-lerntheoretischen Bedeutung der Erkenntnis- und Wissestheorie Michael Polanyis.[Craftsmanship and implicit knowledge. For a gauge-learning theoretical importance of knowledge and knowledge theory Michael Polanyi] Münster u.a.. Waxmann. (In German).

7. Refleksija [Reflection] http://www.letonika.lv/ (15.03.2014) (in Latvian).

8. Schön, D. (1983). The Refkective Practitioner. How Professioals Think in Action. London. Temple Smith.

9. Žogla,I. (1997). Vispārīgā didaktika [General didactics]. Rīga: LU Pedagogijas un psihologijas institūts (in Latvian).

10. Степанова, А. (2009). Методь рефлексии и релаксаџии в учебном процессе. [Methods of reflection and relaxation in the educational process] http://900igr.net/ (16.02.2014) 